\title{
REVIEW
}

\section{Refining the Management of Rheumatoid Arthritis: the Benefits of Subcutaneous Tocilizumab}

\author{
Andra F. Negoescu $\cdot$ Andrew J. K. Östör
}

Received: October 2, 2014 / Published online: December 25, 2014

(C) The Author(s) 2014. This article is published with open access at Springerlink.com

\section{ABSTRACT}

Rheumatoid arthritis (RA) is a chronic systemic autoimmune condition which affects approximately $1 \%$ of the adult population worldwide and is characterized by joint inflammation, with extra-articular features being common. Interleukin 6 (IL-6) is one of the chief pro-inflammatory cytokines found in the joints and sera of patients with RA. Increased levels of IL-6 correlate with inflammation, disease activity, and radiological damage. RA treatment should focus on minimizing the signs and symptoms of disease (pain, stiffness, and swelling of the joints) and on preventing or minimizing joint damage to preserve functionality and quality of life. The benefits of early, intensive intervention are now acknowledged, with all patients with

Electronic supplementary material The online version of this article (doi:10.1007/s40744-014-0007-2) contains supplementary material, which is available to authorized users.

A. F. Negoescu $(\bowtie) \cdot$ A. J. K. Östör

Department of Rheumatology, Addenbrooke's

Hospital, Cambridge University Hospitals NHS

Foundation Trust, Hills Road, Cambridge CB2 0QQ,

UK

e-mail: a.negoescu@doctors.org.uk newly diagnosed, active RA being started on methotrexate (MTX) monotherapy or combination therapy. Lack of efficacy, intolerance, and/or toxicity can lead to discontinuation of this drug, and there is a need for exploring further treatment options. In the UK, patients with persistently high disease activity who have failed at least two conventional disease-modifying agents (DMARDs) including MTX may qualify for biologic therapy. Numerous trials have shown intravenous (IV) tocilizumab (TCZ), a biologic drug targeting and inhibiting IL-6, to be effective for controlling inflammation in RA, with an acceptable safety profile. Its superiority in monotherapy when compared with other biologic agents makes it the drug of choice for patients who are intolerant or have contraindications to traditional DMARDs. However, one of the drawbacks of IV TCZ is the requirement for monthly infusions, which is inherently inconvenient for the patient and associated with increased cost. Subcutaneous (SC) TCZ has now been approved following two clinical trials which showed similar efficacy and safety compared to IV TCZ, and better efficacy compared to placebo (SUMMACTA and 
BREVACTA trials, respectively). Respiratory infections are the most common side effects in patients receiving SC TCZ. Advantages of SC formulations include convenience and reduced cost compared with IV therapies. Overall, patients tend to have a preference for SC over IV administration of medications. Close monitoring of patients should be undertaken in all cases, paying particular attention to the full blood count, liver enzymes, and cholesterol levels.

Keywords: Disease-modifying Interleukin-6; Rheumatoid Tocilizumab

\section{INTRODUCTION}

Rheumatoid arthritis (RA) is a chronic systemic autoimmune condition characterized by joint inflammation, although extra-articular features are common. RA affects approximately $1 \%$ of the adult population worldwide and is more common in women $[1,2]$. The incidence of RA in the UK is 36 per 100,000 women and 14 per 100,000 men per year $[1,2]$ and RA may lead to significant disability, reduced quality of life, and increased mortality [1, 3-5]. Furthermore, it has a significant impact on work productivity, with approximately one-third of patients having to leave employment within 2 years of diagnosis [6].

\section{Joint Involvement in Rheumatoid Arthritis}

Although typically a disease of the hands and feet, RA may affect any synovial joint. Inflammation of the synovium, followed by progressive degradation of cartilage and subsequent bone erosion are the hallmark of active untreated disease.

\section{Systemic Effects of Rheumatoid Arthritis}

In addition to joint destruction, RA can result in a variety of extra-articular manifestations including anemia, localized and generalized osteoporosis [7, 8], nodulosis, eye disease, and pulmonary and cardiovascular (CV) disease [9, 10]. Being diagnosed with RA is an independent risk factor for atherosclerosis (similar in severity to type 2 diabetes mellitus) due to chronic, systemic inflammation [11-13]. CV disease has emerged as the number one cause of mortality in patients with RA [14, 15].

\section{Immunopathogenesis}

The articular and extra-articular manifestations of RA are caused at a molecular level by increased levels of pro-inflammatory cells, cytokines, and autoantibody production [8]. Pro-inflammatory cytokines, such as tumor necrosis factor alpha (TNF- $\alpha$ ), interleukin 1 (IL1), interleukin 6 (IL-6), interleukin 17 (IL-17), interferon gamma (IFN- $\gamma$ ), and transforming growth factor beta (TGF- $\beta$ ), can stimulate the release of further cytokines [16-19], leading to excessive cellular activation and migration into the synovium and sustained inflammation [16, $17,19]$.

\section{THE ROLE OF IL-6 IN RHEUMATOID ARTHRITIS}

IL-6 is one of the chief pro-inflammatory cytokines found in the joints and sera of patients with RA [20-23]. A number of cell types produce and release IL-6, including activated macrophages, synovial fibroblasts, 
and $\mathrm{T}$ and $\mathrm{B}$ cells $[8,24-26]$. Increased levels of IL-6 correlate with inflammation, disease activity, and radiological damage [8, 24, 2730]. Furthermore, the decrease in serum IL-6 levels in the first 12 months of therapy with disease-modifying agents (DMARDs) is a powerful prognostic marker for clinical outcomes [28].

\section{CURRENT TREATMENTS FOR RHEUMATOID ARTHRITIS}

\section{Non-steroidal Anti-inflammatory Drugs and Traditional DMARDs}

Treatment for RA should focus on minimizing the signs and symptoms of the disease (pain, stiffness, and swelling of the joints) and on preventing or minimizing joint damage to preserve functionality and quality of life. In addition, reducing the extra-articular manifestations and implicitly reducing the premature mortality associated with the condition is critical [31, 32].

Suppression of inflammation is the central element of RA management, with remission (defined as the complete suppression of inflammation and prevention of joint destruction) being the ultimate goal of therapy $[16,19,33]$. Non-steroidal antiinflammatory drugs (NSAIDs) may provide fast and effective relief of symptoms, but do not alter the disease course. The cornerstone of therapy, therefore, is DMARDs, which should be instituted as early as possible to prevent long-term joint damage [34-36]. For safety and efficacy reasons, patients should be frequently monitored and treatment altered accordingly, adopting a treat to target strategy [37].

Although highly effective in many cases, traditional DMARDs [such as methotrexate
(MTX), sulfasalazine (SSZ), leflunomide (LEF), and hydroxychloroquine (HCQ)] can be associated with toxicity and/or intolerability, with a high impact on adherence and thus on disease control [38-41].

The benefits of early, intensive intervention are now acknowledged, with all patients with newly diagnosed, active RA being started on MTX monotherapy or combination therapy (usually with HCQ). The pre-eminent DMARD is MTX; however, lack of efficacy, intolerance, and/or toxicity can lead to discontinuation [40], and with it the need of exploring further treatment options.

\section{Biologic Agents}

Biologic agents target specific pro-inflammatory cytokines, cells, or molecules involved in the pathogenesis of RA [16]. Five anti-TNF- $\alpha$ therapies (infliximab, adalimumab, etanercept, certolizumab, and golimumab) are currently licensed in Europe and the USA [16, 19]. Although TNF-inhibitors have revolutionized RA treatment over the last decade or so, there remains an area of unmet need, with up to $40 \%$ of patients failing to respond to this particular treatment $[16,19,42]$. Other disadvantages of TNF- $\alpha$ inhibitors include contraindications such as heart failure, chronic or recurrent infections, and demyelinating conditions, as well as side effects that can lead to treatment discontinuation (serious infections, injection site reactions (ISR), melanoma, non-melanoma skin malignancies [43], and lupus-like illness). Reactivation of latent tuberculosis (TB) infection may occur; however, this has been minimized by screening programs and the use of prophylactic anti-TB agents in those at risk.

Due to the area of unmet needs, other biologic agents have been trialed in RA. Anakinra, an IL-1 inhibitor, was one of the 
first biologics studied in RA [44]; however, it is no longer used due to its lower efficacy compared with other agents and the poor tolerability of daily subcutaneous (SC) injections. Rituximab (RTX), an anti-CD20 found on B cells, is now well established for the treatment of RA [45]. Further biologic agents include abatacept which inhibits the co-stimulation of $\mathrm{T}$ cells [46], and tocilizumab (TCZ), an IL-6 receptor antagonist [47]. Whereas RTX is administered by intravenous (IV) infusion no less frequently than 6 monthly, the latter two agents were initially administered as IV infusions; however, SC formulations are now available [48-51]. This article will specifically focus on SC TCZ including its safety, efficacy, and how it may fit in RA treatment regimens. Furthermore, this article is based on previously conducted studies and does not involve any new studies of human or animal subjects performed by any of the authors.

\section{EFFICACY OF SUBCUTANEOUS TOCILIZUMAB IN RHEUMATOID ARTHRITIS}

Numerous trials have shown IV TCZ to be an effective drug for controlling inflammation in RA with an acceptable safety profile [47, 52-56]. Its superiority in monotherapy when compared with other biologic agents makes it the drug of choice for patients who are intolerant or have contraindications to traditional DMARDs [36]. However, one of the drawbacks of IV TCZ is the requirement for monthly infusions with the inherent inconvenience for the patient and cost. Two phase III clinical trials have led to the approval of SC TCZ, having shown the efficacy and tolerability of SC TCZ in RA [50, 51].
The SUMMACTA trial (ClinicalTrials.gov \#NCT01194414) compared SC and IV TCZ and met its primary end point, showing that TCZ SC $162 \mathrm{mg}$ weekly is non-inferior to TCZ IV $8 \mathrm{mg} /$ $\mathrm{kg}$ in terms of efficacy [50]. The American College of Rheumatology 20 (ACR 20) response was achieved in $69.4 \%$ of patients at week 24 in the TCZ SC group, compared with $73.4 \%$ in the TCZ IV group. The difference of $-4.0 \%$ (95\% confidence interval [CI] -9.2 to 1.2) met the requirement for the non-inferiority of TCZ SC to TCZ IV. The ACR 50 and ACR 70 response rates at 24 weeks were also similar between groups (weighted differences of ACR 50 and ACR 70 responders at week $24:-1.8$ and $-3.8 \%$, respectively).

Disease Activity Score in 28 Joints (DAS 28) remission was another clinical outcome measured in the SUMMACTA trial [50]. The proportion of patients who achieved DAS 28 remission at week 24 was similar in both SC and IV groups, with a weighted difference of $0.9 \%$. The non-inferiority of SC TCZ to IV TCZ was also demonstrated for functionality outcomes, with a weighted difference of $-2.3 \%$ in the proportion of patients achieving a decrease of 0.3 or greater in Health Assessment Questionnaire Disability Index (HAQ-DI) from baseline (Fig. 1).

The BREVACTA trial (ClinicalTrials.gov \#NCT01232569) studied the efficacy and safety of SC TCZ compared to SC placebo in patients with RA who had an inadequate response to traditional DMARDs [51]. The study met its primary end point, showing the superiority of SC TCZ (162 mg every 2 weeks) to SC placebo in achieving ACR 20 response at week $24 \quad[60.9$ and $31.5 \%$, respectively; weighted difference $29.5 \%$ [95\% CI 22.0-37.0; $P<0.0001]$ ). In a similar trend, ACR 50 and ACR 70 response rates at week 24 were significantly higher in the SC TCZ group 

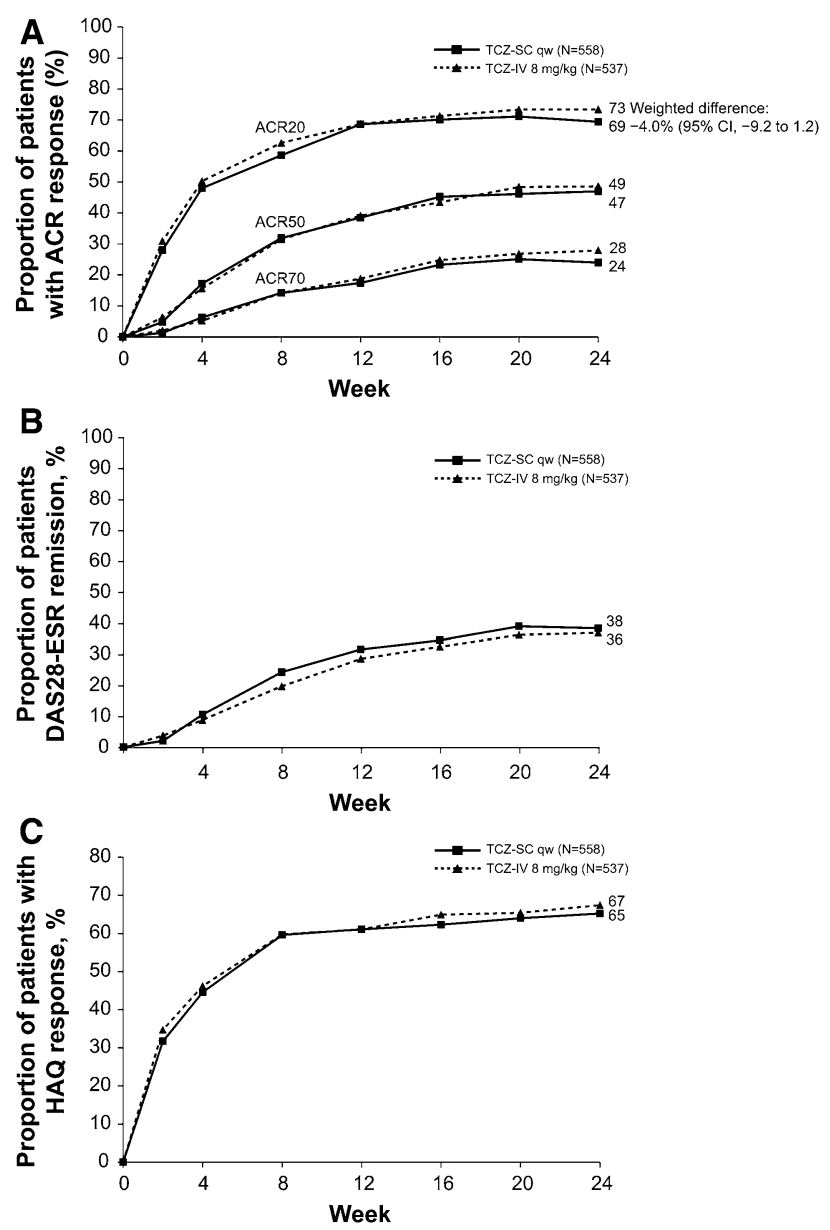

Fig. 1 Disease activity and physical function over 24 weeks for patients in the per-protocol (PP) population. a Proportion of patients in the PP population treated with either subcutaneous tocilizumab (TCZ SC; $n=558$ ) or intravenous tocilizumab (TCZ IV; $n=537$ ) achieving 20, 50 , and $70 \%$ improvements per American College of Rheumatology criteria (ACR20, ACR50, and ACR70, respectively) over 24 weeks. b Proportion of patients

\section{(27.9\% [95\% CI 21.5-34.4; $P<0.0001]$ and} $14.8 \% \quad[95 \% \quad$ CI $\quad 9.8-19.9 ; \quad P<0.0001]$, respectively). DAS 28 remission (defined as DAS $28<2.6$ ) was significantly higher at week 24 in the SC TCZ group compared to the placebo group (weighted difference $28.6 \%$ [95\% CI 22.5-35.2; $P<0.0001]$ ). The mean change from baseline at week 24 in the total Sharpe score was lower in the SC TCZ group compared to the placebo group $(0.62 \pm 2.692$ achieving remission based on disease activity score using 28 joints (DAS 28) based on erythrocyte sedimentation rate (ESR <2.6) over 24 weeks. c Proportion of patients achieving a health assessment questionnaire (HAQ) response (improvement of $\geq 0.3$ from baseline) over 24 weeks. Reproduced from: Burmester et al. [50] with permission from BMJ Publishing Group Ltd. $q w$ weekly

vs. $1.23 \pm 2.816$ ), with a significant difference in the erosion score and a non-statistically significant difference in the joint space narrowing score.

\section{SAFETY OF SUBCUTANEOUS TOCILIZUMAB}

The safety of SC TCZ was also assessed in the SUMMACTA (Table 1) and BREVACTA studies. 
Table 1 Safety summary (safety population)

\begin{tabular}{|c|c|c|}
\hline & $\begin{array}{l}\text { Tocilizumab SC } 162 \mathrm{mg} \\
\text { qw }(n=631) 289.82 \mathrm{PY}\end{array}$ & $\begin{array}{l}\text { Tocilizumab IV } 8 \mathrm{mg} / \mathrm{kg} \\
\mathrm{q} 4 \mathrm{w}(n=631) 288.39 \mathrm{PY}\end{array}$ \\
\hline \multicolumn{3}{|l|}{$\mathrm{AE}$} \\
\hline Total AE, $n$ & 1,747 & 1,697 \\
\hline Patients with $>1 \mathrm{AE}, n$ (\%) & $481(76.2)$ & $486(77.0)$ \\
\hline Discontinuation due to $\mathrm{AE}, n(\%)$ & $30(4.8)$ & $42(6.7)$ \\
\hline \multicolumn{3}{|l|}{ SAE } \\
\hline Total SAE, $n$ & 34 & 43 \\
\hline Patients with $>1$ SAE, $n(\%)$ & $29(4.6)$ & $33(5.2)$ \\
\hline SAE per 100 PY (95\% CI) & $11.73(8.12-16.39)$ & $14.91(10.79-20.08)$ \\
\hline \multicolumn{3}{|l|}{ SI } \\
\hline Total SI & 9 & 9 \\
\hline Patients with $>1$ SI, $n(\%)$ & $9(1.4)$ & $9(1.4)$ \\
\hline SI per 100 PY (95\% CI) & $3.11(1.25-5.89)$ & $3.47(1.66-6.38)$ \\
\hline Serious hypersensitivity reactions ${ }^{\mathrm{a}}, n(\%)$ & $2(<1)$ & $3^{\mathrm{b}}(<1)$ \\
\hline \multicolumn{3}{|l|}{ ISR } \\
\hline Patients with ISR, $n(\%)$ & $64(10.1)$ & $15(2.4)$ \\
\hline ISR, $n$ & 168 & 94 \\
\hline Erythema, $n(\%)$ & $28(4.4)$ & $5(0.8)$ \\
\hline Pain, $n(\%)$ & $12(1.9)$ & $5(0.8)$ \\
\hline Pruritus, $n(\%)$ & $14(2.2)$ & $0(0)$ \\
\hline Hematoma, $n(\%)$ & $5(0.8)$ & $5(0.8)$ \\
\hline Dose interruption or study withdrawal because of ISR, $n$ & 0 & 0 \\
\hline Death, $n(\%)$ & $0(0)$ & $1(<1)$ \\
\hline
\end{tabular}

Reproduced from Burmester et al. [50] with permission from BMJ Publishing Group Ltd.

$A E$ adverse event, $I S R_{r}$ injection site reaction, $I V$ intravenous, $P Y$ patient-years, $q w_{r}$ every week, $q 4 w_{r}$ every 4 weeks, $S A E$ serious adverse event, $S C$ subcutaneous, $S I$ serious infection

a Serious hypersensitivity was defined as an SAE occurring during or within $24 \mathrm{~h}$ of the injection or infusion, excluding ISR, and evaluated as 'related' to study treatment by the investigator

${ }^{b}$ Of the three events in the tocilizumab IV group, one was cellulitis and one was retinal artery occlusion; these two events were not considered consistent with a serious hypersensitivity reaction

In the SUMMACTA trial a similar safety profile was found between the IV and SC groups, with the exception of a higher incidence of ISR for the SC group, as would be expected [168 ISR in the SC group (10.1\% of patients) vs. 94 ISR in the IV group (2.4\%)]. However, ISR were all deemed non-serious and did not require treatment interruptions or discontinuation [50]. The most common side effect described in the studies was infection, particularly upper 
respiratory tract infection $(7.3 \%$ TCZ SC and $11.6 \%$ TCZ IV). Serious infections were rare, but reported in both groups (pneumonia-two cases in each group). Septic arthritis occurred in two patients in the IV group, with one case progressing to sepsis and death. No deaths were reported in the SC group $(0 / 631 ; 1 / 631$ in the IV group). The most common cause for study discontinuation due to side effects was infection in both groups $(1.1 \%$ TCZ SC and 1.3\% TCZ IV).

The use of TCZ leads to a strong decrease in C-reactive protein: this makes the clinical evaluation of patients with a possible septic disorder much more difficult. Other wellrecognized side effects of $\mathrm{TCZ}$ are its effects on liver function tests (LFTs), neutrophils, and cholesterol levels. Raised LFTs were seen in the SUMMACTA, as well as BREVACTA trials. No differences between groups were observed for alanine-transaminase (ALT) and aspartatetransaminase (AST) rises from normal to a value more than three times the upper limit of normal which occurred in 4.8 vs. $5.1 \%$ of patients for ALT and 1 vs. $1.3 \%$ for AST, in the SC and IV TCZ groups, respectively [50].

Neutropenia $>1,000 \times 10^{9} / \mathrm{L}$ was reported in a slightly higher proportion in the SC group compared to the IV group (32.8 vs. $23.3 \%$ ); however, there was no difference between groups with regard to severe neutropenia $\left(<1,000 \times 10^{9} / \mathrm{L}\right), 2.7$ and $3.2 \%$, respectively. Increases in total cholesterol levels were also more frequent in the SC group compared to the IV group (23.8 vs. $20.6 \%$ ), but with similar proportions between groups with regard to rises in low-density lipoprotein cholesterol, highdensity lipoprotein cholesterol, and triglyceride levels [50].

The BREVACTA trial showed similar safety findings, with respiratory infections being the most common side effects, $6.4 \%$ in each group
[51]. The most common ISR were erythema, pruritus, and pain, and the proportion was higher in the SC TCZ group compared to the placebo group (7.1 and 4.1\%, respectively). No anaphylaxis or serious hypersensitivity reactions were reported. Only $6.3 \%$ of patients discontinued SC TCZ due to adverse events (most commonly due to infections and raised LFTs).

Infection was reported as the most common serious adverse event $(2.1 \%$ in the SC TCZ group vs. $1.8 \%$ in the placebo group). Three deaths (3/ 437 ) were reported by week 24 , all in the SC TCZ group (one death attributable to hemophilus influenza sepsis, one to sepsis with pancytopenia likely of gastrointestinal origin, and one to lower respiratory tract infection). No gastrointestinal perforation was reported up to week 24, although one event of diverticular hemorrhage was described in the SC TCZ group, in a patient with a history of diverticular bleeding. All patients were screened for TB and those with active TB were excluded.

In patients who experienced elevated LFTs, most had an increase less than three times the upper limit of normal, with shifts occurring more frequently in the SC TCZ group compared to the placebo group (33 vs. 13\%). Patients experienced a decreased neutrophil count $\left(>1,000 / \mathrm{mm}^{3}\right)$ in a higher proportion in the SC TCZ group (16.7 vs. 3.7\%), while severe neutropenia $\left(<1,000 / \mathrm{mm}^{3}\right)$ was only registered in the SC TCZ group (3.7\%). No events of severe thrombocytopenia $\left(<50,000 / \mathrm{mm}^{3}\right)$ occurred. The proportion of patients with cholesterol level shifts from $<200 \mathrm{mg} / \mathrm{dL}$ at baseline to $\geq 200 \mathrm{mg} / \mathrm{dL}$ was higher in the SC TCZ group compared to the placebo group (45 and 14\%, respectively). Increases in low-density lipoprotein cholesterol and triglyceride levels also occurred more frequently in the SC TCZ group compared to the placebo group. 


\section{THE CURRENT RHEUMATOID ARTHRITIS TREATMENT PATHWAY AND SUBCUTANEOUS TOCILIZUMAB}

Current guidelines recommend that newly diagnosed patients with moderate to severe RA are commenced on a combination of DMARDs, usually hydroxychloroquine and methotrexate or possibly MTX monotherapy $[34,36]$. The most important element of treatment, however, is that patients are seen and started on immunosuppression as early as possible, to optimize outcomes [57].
In the UK, patients with persistently high disease activity (two DAS 28 scores $>5.1$ at least 1 month apart) who have failed at least two conventional DMARDs trialed (including MTX) for a minimum of 6 months at the standard dose (or less if treatment resulted in side effects) may qualify for biologic therapy (see Fig. 2). According to the National Institute for Health and Care Excellence (NICE) and European League Against Rheumatism (EULAR) recommendations, three classes of biologic agents can be given as first line to patients with active RA:

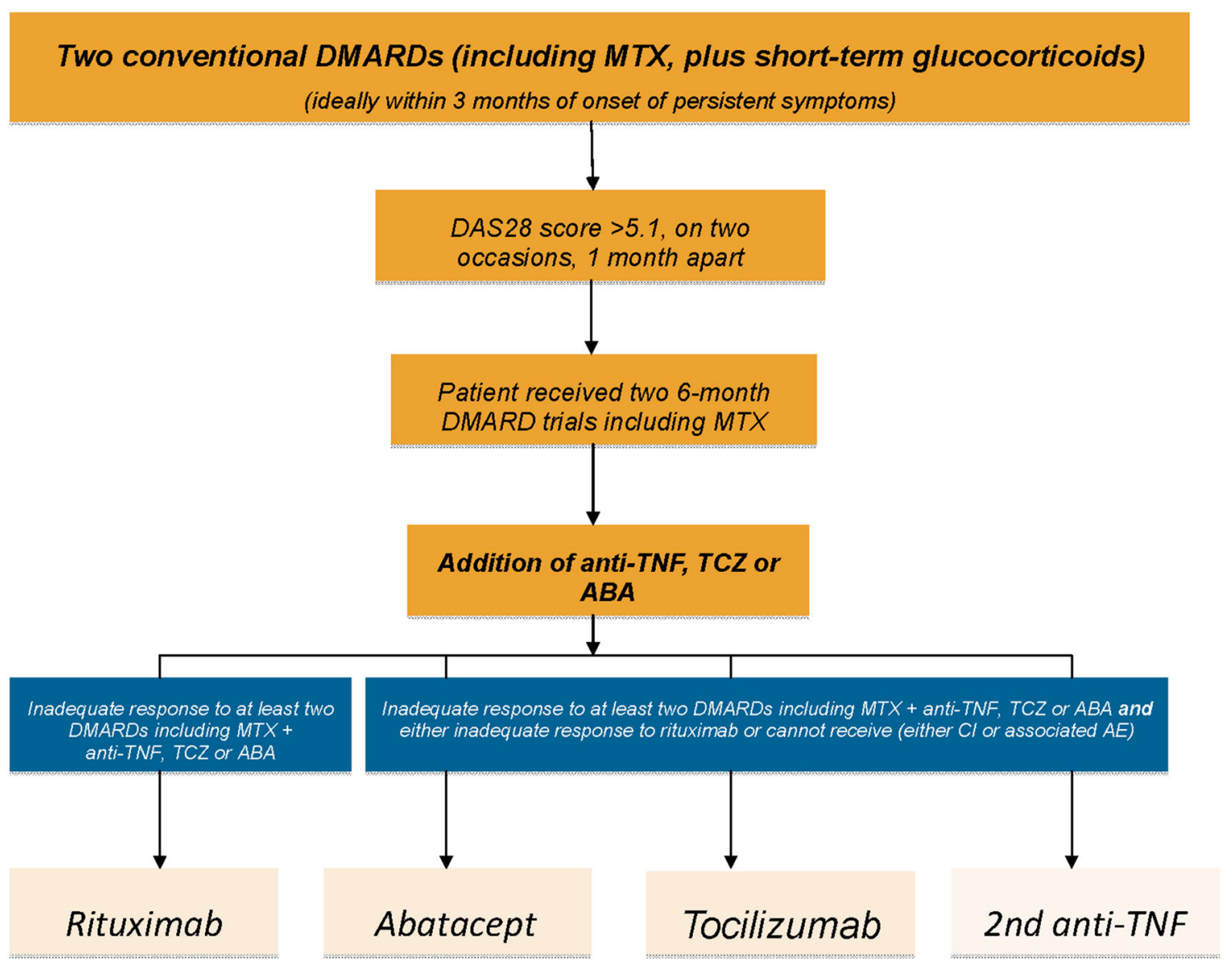

Fig. 2 NICE rheumatoid arthritis clinical treatment pathway. $A B A$ abatacept, $A E$ adverse events, $C I$ contraindications, DAS 28 Disease Activity Score in 28 Joints, DMARD disease-modifying antirheumatic drug, $M T X$ methotrexate,

NICE National Institute for Health and Care Excellence, $R A$ rheumatoid arthritis, $T C Z$ tocilizumab, $T N F$ tumor necrosis factor 
1. Anti-TNF $\alpha$, with a choice of five agents (adalimumab, etanercept, golimumab, certolizumab, and infliximab), all of which are available by SC apart from infliximab which is administered by IV infusion;

2. Abatacept (available both by IV and SC);

3. TCZ, (available both by IV and SC).

NICE guidelines follow European Commission and Food and Drug Administration (FDA) approval of SC TCZ for the treatment of moderate to severe RA in patients who are either intolerant to or have failed to respond to other RA treatments, in April and October 2013, respectively. This approval made TCZ the first anti-IL-6 receptor biologic available as SC and IV formulations for both mono and combination therapy with MTX [58]. TCZ can also be given as third line for patients with RA, after failure/intolerance to anti-TNF $\alpha$ and RTX, or as second line, if contraindications to RTX exist (see Fig. 2).

\section{PRACTICAL ASPECTS OF SUBCUTANEOUS FORMULATION}

The advantages of SC formulations include convenience and reduced cost compared with IV therapies. Time off work or usual activities to attend pre-booked IV infusions requires significant infrastructure and is not patient focused. Self-administration (following appropriate training) is ideal for many patients such as those with full-time work commitments, child care issues, and who travel frequently. Overall, patients tend to have a preference for SC over IV administration of medications [59-61]. However, there are patients for whom IV administration is more suitable. These include patients with extensive hand deformities or who have needle phobia, and those where there is concern regarding drug compliance.

Regardless, close monitoring of patients should be undertaken in all cases paying particular attention to the full blood count, liver enzymes, and cholesterol levels. The British Society for Rheumatology (BSR) has published national guidelines for patients receiving IV TCZ, although local policies may differ [62]. The IV TCZ guidelines for patients with RA will be used as a proxy for monitoring the SC TCZ formulation. In addition, as neutropenia and cholesterol level shifts are more frequent in the SC group, we suggest that closer monitoring of these parameters should be performed for patients prescribed SC formulation. The summary of recommendations is as follows:

1. Baseline fasting lipid profile (if abnormal, treatment should be given in accordance with local guidelines); lipid profile should be repeated in 3 months and treatment instituted/altered if appropriate.

2. Four-weekly monitoring of the absolute neutrophil count for the first 6 months, then less frequently if severe neutropenia does not occur.

3. Four-weekly monitoring of LFTs for the first 6 months (and every 2-3 months thereafter if stable), caution when using other hepatotoxic drugs, and education with regard to reducing alcohol consumption.

4. Four-week interruption of TCZ prior to elective joint replacement surgery, to reduce the risk of post-operative infection. TCZ can be restarted once infection is excluded and the wound has healed.

5. TCZ should be stopped at least 3 months prior to planned conception and should not be given to women who breastfeed.

6. Annual influenza vaccine and pneumococcal vaccination are 
recommended and should be encouraged, while live attenuated vaccines are contraindicated.

7. TCZ should be used with caution in patients who have a history of diverticulitis, or are taking corticosteroids and/or NSAIDs, due to the risk of gastro-intestinal perforation.

\section{TOCILIZUMAB MONOTHERAPY IN RHEUMATOID ARTHRITIS}

It would appear that there is an advantage in using TCZ as monotherapy compared with other biologic agents [63]. This has particular relevance as MTX is poorly tolerated in a substantial number of patients [40].

The AMBITION trial (ClinicalTrials.gov \#NCT00109408) compared TCZ monotherapy $(8 \mathrm{mg} / \mathrm{kg}$ every 4 weeks) with MTX monotherapy in patients with active RA (including a high proportion of patients with early disease) over 24 weeks [52]. Results showed superiority of TCZ monotherapy, with a significant improvement in disease signs and symptoms. The weighted difference for ACR 20 response at week 24 was $0.19 \quad(95 \%$ CI $0.11-0.27, P<0.001)$. TCZ was also superior to placebo at week 8 (ACR 20 remission: 55.6 vs. $13.1 \%$ ) with a weighted difference of 0.43 . The superiority of TCZ was also seen in MTX-naive patients (ACR 20 remission: 53.7 vs. 68.6\%; ACR 50 remission: 33.2 vs. $45 \%$; ACR 70 remission: 14.2 vs. $27.2 \%$ in the MTX and TCZ groups, respectively).

DAS 28 at week 24 also improved in a higher proportion in the TCZ group compared to MTX group (adjusted mean change from baseline: -3.31 vs. -2.05 ) and the proportion of patients in remission at week 24 (DAS $28<2.6$ ) was higher in the TCZ group (32 vs. 4\%). An increase in hemoglobin $(\mathrm{Hb})$ levels was seen in the TCZ group (by $1.19 \mathrm{~g} / \mathrm{dL}$ from baseline), more so than in the MTX group, with an increase only by $0.10 \mathrm{~g} / \mathrm{dL}$ at week 24 . Normalization of mean $\mathrm{Hb}$ (from a level less than the lower limit of normal at baseline) occurred in the TCZ group by week 6 , and the effect was maintained to week 24 . This effect was not seen in the MTX group. Patients in the TCZ group also had a greater improvement in physical function as measured by HAQ-DI $(-0.7$ vs. -0.5 from baseline). This is the only study to date which has shown clinical superiority of a biologic agent given as monotherapy compared with MTX monotherapy [52].

In addition, the recently published ADACTA trial, a head-to-head monotherapy trial comparing TCZ with adalimumab (ADA) in patients with active RA who had failed or developed side effects to MTX, showed superiority of TCZ monotherapy (DAS 28 mean change from baseline: -3.3 in the TCZ group vs. -1.8 in the ADA group, difference $-1.5,95 \%$ CI -1.8 to $-1.1 ; P<0.0001$ ) [64]. Starting with week 16 , more patients in the TCZ group received ACR and EULAR remission [33], compared to the ADA group (in ADACTA). Physical function as assessed by the HAQ-DI score improved more significantly in the TCZ group than in the ADA group (change from baseline to week 24 : -0.7 vs. -0.5 ; difference between adjusted means: $-0.2,95 \% \mathrm{CI}-0.3$ to $0.0 ; P=0.0653)$. The proportion of patients with HAQ-DI improvement of at least 0.22 from baseline to week 24 was higher in the TCZ group compared to the ADA group (56.4 vs. $51.2 \%$ ). This data suggest that TCZ is a preferable biologic agent for patients with active RA who are intolerant to traditional DMARDs [36].

The MUSASHI trial (ClinicalTrials.jp \#JapicCTI-101117), a recent phase III study on Japanese patients, assessed the efficacy and 
safety of SC vs. IV TCZ monotherapy in patients with RA [65]. The study met its primary end point, demonstrating the non-inferiority of TCZ SC monotherapy to TCZ IV monotherapy. The ACR 20 response rate at week 24 was achieved in $79.2 \%(95 \%$ CI $72.9,85.5)$ of patients in the SC group and $88.5 \%(95 \%$ CI $83.4,93.5)$ in the IV group (weighted difference $-9.4 \%$ [95\% CI $-17.6,-1.2])$.

ACR 50 and ACR 70 response rates at week 24 were also similar between groups. DAS 28-erythrocyte sedimentation rate (ESR), Clinical Disease Activity Index (CDAI), and Boolean Index remission rates at week 24 were $49.7,16.4$, and $15.7 \%$, respectively, in the SC group, and 62.2, 23.1, and $16.0 \%$, respectively, in the IV group. DAS 28-ESR low disease activity at week 24 was achieved in a higher proportion in the IV group $(82.1 \%$ [95\% CI 76.0, 88.1]) than in the SC group (65.4\% [95\% CI 58.0, 72.8]). Physical function improvement was assessed by HAQ-DI and defined as a change of -0.3 units from baseline at week 24 . This was $56.6 \%(95 \%$ CI $48.9,64.3)$ and $67.9 \%(95 \%$ CI $60.6,75.3)$ in the SC and IV groups, respectively.

The safety profiles were comparable between groups, with the exception of ISRs, which occurred more frequently in the SC group than in the IV group. Over 24 weeks, AEs occurred in $89.0 \%(154 / 173)$ and $90.8 \%(157 /$ 173), SAEs in $7.5 \%(13 / 173)$ and $5.8 \%(10 / 173)$, adverse drug reactions in $83.2 \%(144 / 173)$ and $86.1 \%(149 / 173)$ of patients, and serious adverse drug reactions in 3.5\% (6/173) and 5.8\% (10/ 173) of patients in the SC and IV groups, respectively. No deaths or malignancies were reported.

Infections were reported in 41.6 and $45.1 \%$ of patients in the SC and IV groups, respectively. Nasopharyngitis was the most common event $(17.9 \%$ in the SC group and
$20.8 \%$ in the IV group). Serious infections (herpes zoster, pneumonia, cellulitis, gastroenteritis) occurred in $1.2 \%$ of patients in the SC group and in $2.9 \%$ of patients in the IV group. ISRs were reported in $12.1 \%$ of patients in the SC group and in $5.2 \%$ in the IV group (placebo injection). All ISRs were mild and no cases resulted in discontinuation from the study. One patient $(0.6 \%)$ in the IV group had an anaphylactic reaction after the second infusion and was withdrawn from the study. There were no cases of serious hypersensitivity in the SC group. The proportion of patients experiencing elevations in lipid levels and LFTs was similar between groups. Increases in total cholesterol from $<200 \mathrm{mg} / \mathrm{dL}$ at baseline to $\geq 200 \mathrm{mg} / \mathrm{dL}$ occurred in 56.1 and $53.7 \%$ of cases in the SC and IV groups, respectively. Grade 1 and 2 shifts in ALT and AST were reported in $22.5 \%$ of patients in both SC and IV groups (ALT) and 12.8 versus $18 \%$ in the SC and IV groups, respectively (AST). Grade 3 shifts were rare ( 1 patient in the SC group and 2 patients in the IV group for ALT, 1 patient in the SC group for AST). There were no grade 4 shifts in LFTs reported. A proportion of $2.9 \%$ of patients experienced grade 3 neutropenia (500-1,000 cells $\left./ \mathrm{mm}^{3}\right)$ in each group, with 1 patient in the SC group being withdrawn from the study. No grade 4 neutropenia $\left(<500 / \mathrm{mm}^{3}\right)$ was reported.

\section{CONCLUSION}

Following the success of IV TCZ, the arrival of SC TCZ is a welcome addition to the arsenal to combat the morbidity and premature mortality associated with RA. The efficacy of SC TCZ in both monotherapy and combination therapy and the acceptable safety profile are reassuring; however, longer-term data are required. Certain groups of patients may benefit, especially those 
intolerant to traditional DMARDs. Increasingly, SC TCZ will be incorporated into management paradigms to optimize the outcomes for all RA patients.

\section{ACKNOWLEDGMENTS}

No funding or sponsorship was received for this study or publication of this article. All named authors meet the ICMJE criteria for authorship for this manuscript, take responsibility for the integrity of the work as a whole, and have given final approval for the version to be published. During the peer review process, the manufacturer of the agent under review was offered an opportunity to comment on the article. Changes resulting from comments received were made by the author based on their scientific and editorial merit.

Conflict of interest. Andra F. Negoescu has received support from (including attendance at conferences) Pfizer and Abbvie and undertakes clinical trials for Roche, MSD, Abbvie, Pfizer, Novartis, Lilly, and BMS. Andrew J. K. Östör has received support from (including attendance at conferences), undertakes clinical trials, and acts as a consultant to Roche, Chugai, MSD, Abbvie, Pfizer, Novartis, Napp, Lilly, and BMS.

Compliance with ethics guidelines. This article is based on previously conducted studies, and does not involve any new studies of human or animal subjects performed by any of the authors.

Open Access. This article is distributed under the terms of the Creative Commons Attribution License which permits any use, distribution, and reproduction in any medium, provided the original author(s) and the source are credited.

\section{REFERENCES}

1. World Health Organization (WHO). Chronic rheumatic conditions. Available from: http://www. who.int/chp/topics/rheumatic/en/print.html. Accessed December 10, 2014.

2. Symmons DP, Barrett EM, Bankhead CR, Scott DG, Silman AJ. The incidence of rheumatoid arthritis in the United Kingdom: results from the Norfolk Arthritis Register. Br J Rheumatol. 1994;33:735-9.

3. Watson DJ, Rhodes T, Guess HA. All-cause mortality and vascular events among patients with rheumatoid arthritis, osteoarthritis, or no arthritis in the UK General Practice Research Database. J Rheumatol. 2003;30:1196-202.

4. National Institute for Clinical Excellence. Review of Clinical Guideline (CG79)—Rheumatoid Arthritis. London: NICE, 2009. Available from: https://www. nice.org.uk/guidance/cg79/resources/rheumatoidarthritis-consultation-document2. Accessed December 10, 2014.

5. National Collaborating Centre for Chronic Conditions. Rheumatoid arthritis: national clinical guideline for management and treatment in adults. London: RCP, 2009. Available from: https://www. rcplondon.ac.uk/sites/default/files/documents/rheu matiod-arthritis-guideline.pdf. Accessed December 10, 2014.

6. Goodson NJ, Farragher TM, Symmons DP. Rheumatoid factor, smoking, and disease severity: associations with mortality in rheumatoid arthritis. J Rheumatol. 2008;35:945-9.

7. Young A, Koduri G. Extra-articular manifestations and complications of rheumatoid arthritis. Best Pract Res Clin Rheumatol. 2007;21:907-27.

8. Yoshizaki K, Nishimoto N, Mihara M, Kishimoto T. Therapy of rheumatoid arthritis by blocking IL-6 signal transduction with a humanized anti-IL-6 receptor antibody. Springer Semin Immunopathol. 1998;20:247-59.

9. Nannini C, Ryu JH, Matteson EL. Lung disease in rheumatoid arthritis. Curr Opin Rheumatol. 2008;20:340-6.

10. del Rincón ID, Williams K, Stern MP, Freeman GL, Escalante A. High incidence of cardiovascular events in a rheumatoid arthritis cohort not explained by traditional cardiac risk factors. Arthritis Rheum. 2001;44:2737-45.

11. Puttevils D, De Vusser P, Geusens P, et al. Increased cardiovascular risk in patients with rheumatoid arthritis: an overview. Acta Cardiol. 2014;69:111-8. 
12. Scarno A, Perrotta FM, Cardini F, et al. Beyond the joint: Subclinical atherosclerosis in rheumatoid arthritis. World J Orthop. 2014;5:328-35.

13. Kerekes G, Nurmohamed MT, González-Gay MA, et al. Rheumatoid arthritis and metabolic syndrome. Nat Rev Rheumatol. 2014;10:691-6.

14. Maradit-Kremers $\mathrm{H}$, Nicola PJ, Crowson CS, Ballman KV, Gabriel SE. Cardiovascular death in rheumatoid arthritis: a population-based study. Arthritis Rheum. 2005;52:722-32.

15. Lindhardsen J, Ahlehoff $\mathrm{O}$, Gislason GH, et al. The risk of myocardial infarction in rheumatoid arthritis and diabetes mellitus: a Danish nationwide cohort study. Ann Rheum Dis. 2011;70:929-34.

16. Smolen JS, Steiner G. Therapeutic strategies for rheumatoid arthritis. Nat Rev Drug Discov. 2003;2:473-88.

17. Firestein GS. Evolving concepts of rheumatoid arthritis. Nature. 2003;423:356-61.

18. Gabay C, Kushner I. Acute-phase proteins and other systemic responses to inflammation. N Engl J Med. 1999;340:448-54.

19. Smolen JS, Aletaha D, Koeller $M$, et al. New therapies for treatment of rheumatoid arthritis. Lancet. 2007;370:1861-74.

20. Firestein GS, Alavro-Garcia JM, Maki R. Quantitative analysis of cytokine gene expression in rheumatoid arthritis. Immunology. 1990;144:3342-53.

21. Arvidson NG, Gudbjörnsson B, Elfman L, et al. Circadian rhythm of serum interleukin- 6 in rheumatoid arthritis. Ann Rheum Dis. 1994;53:521-4.

22. Houssiau FA, Devogelaer JP, Van Damme J, et al. Interleukin-6 in synovial fluid and serum of patients with rheumatoid arthritis and other inflammatory arthritides. Arthritis Rheum. 1988;31:784-8.

23. Okamoto $\mathrm{H}$, Yamamura $\mathrm{M}$, Morita $\mathrm{Y}$, et al. The synovial expression and serum levels of interleukin6, interleukin-11, leukemia inhibitory factor, and oncostatin $\mathrm{m}$ in rheumatoid arthritis. Arthritis Rheum. 1997;40:1096-105.

24. Choy E. Clinical experience with inhibition of interleukin-6. Rheum Dis Clin North Am. 2004;30:405-15.

25. Ishihara K, Hirano T. IL-6 in autoimmune disease and chronic inflammatory proliferative disease. Cytokine Growth Factor Rev. 2002;13:357-68.
26. Heinrich PC, Behrmann I, Haan S, et al. Principles of interleukin (IL)-6-type cytokine signalling and its regulation. Biochem J. 2003;374:1-20.

27. Walsh NC, Crotti TN, Goldring SR, et al. Rheumatic diseases: the effects of inflammation on bone. Immunol Rev. 2005;208:228-51.

28. Straub RH, Muller-Ladner $U$, Lichtinger $T$, et al. Decrease of interleukin 6 during the first 12 months is a prognostic marker for clinical outcome during 36 months treatment with disease-modifying antirheumatic drugs. Br J Rheumatol. 1997;36:1298-303.

29. Robak T, Gladalska A, Stepien H, et al. Serum levels of interleukin-6 type cytokines and soluble interleukin-6 receptor in patients with rheumatoid arthritis. Mediat Inflamm. 1998;7:347-53.

30. Jones SA, Richards PJ, Scheller J, et al. IL-6 transsignaling: the in vivo consequences. J Interferon Cytokine Res. 2005;25:241-53.

31. Luqmani R, Hennell S, Estrach C, et al. British Society for Rheumatology and British health professionals in Rheumatology guideline for the management of rheumatoid arthritis (the first 2 years). Rheumatology (Oxford). 2006;45: 1167-9.

32. American College of Rheumatology Subcommittee on Rheumatoid Arthritis Guidelines. Guidelines for the management of rheumatoid arthritis: 2002 Update. Arthritis Rheum. 2002;46:328-46.

33. Felson DT, Smolen JS, Wells G, et al. American college of rheumatology/European League against rheumatism provisional definition of remission in rheumatoid arthritis for clinical trials. Ann Rheum Dis. 2011;70:404-13.

34. NICE guidelines CG79. The management of rheumatoid arthritis in adults. Published February 2009.

35. Singh JA, Furst DE, Bharat A, et al. 2012 Update of the 2008 American College of Rheumatology Recommendations for the use of diseasemodifying antirheumatic drugs and biologic agents in the treatment of rheumatoid arthritis. Arthritis Care Res. 2012;64:625-39.

36. Smolen JS, Landewé R, Breedveld FC, et al. EULAR recommendations for the management of rheumatoid arthritis with synthetic and biological disease-modifying antirheumatic drugs: 2013 update. Ann Rheum Dis. 2014;73:492-509.

37. Smolen JS, Aletaha D, Bijlsma JW, et al. Treating rheumatoid arthritis to target: recommendations of an international task force. Ann Rheum Dis. 2010;69:631-7. 
38. Aletaha D, Kapral T, Smolen JS. Toxicity profiles of traditional disease modifying antirheumatic drugs for rheumatoid arthritis. Ann Rheum Dis. 2003;62:482-6.

39. Choquette D, Thomas O, Arundine M. Lower than expected levels of DMARD acquisition immediately pre and post biologic initiation in rheumatold arthritis patients. Arthritis Rheum. 2012;64:S783.

40. Nikiphorou E, Negoescu A, Fitzpatrick JD, et al. Indispensable or intolerable? Methotrexate in patients with rheumatoid and psoriatic arthritis: a retrospective review of discontinuation rates from a large UK cohort. Clin Rheumatol. 2014;33:609-14.

41. Waimann CA, Marengo MF, de Achaval S, et al. Electronic monitoring of oral therapies in ethnically diverse and economically disadvantaged patients with rheumatoid arthritis: consequences of low adherence. Arthritis Rheum. 2013;65:1421-9.

42. Voll RE, Kalden JR. Do we need new treatment that goes beyond tumor necrosis factor blockers for rheumatoid arthritis? Ann NY Acad Sci. 2005;1051:799-810.

43. Le Blay P, Mouterde G, Barnetche T, et al. Risk of malignancy including non-melanoma skin cancers with anti-tumor necrosis factor therapy in patients with rheumatoid arthritis: meta-analysis of registries and systematic review of long-term extension studies. Clin Exp Rheumatol. 2012;30:756-64.

44. Calabrese LH. Anakinra treatment of patients with rheumatoid arthritis. Ann Pharmacother. 2002;36:1204-9.

45. Smolen JS, Keystone EC, Emery P, et al. Consensus statement on the use of rituximab in patients with rheumatoid arthritis. Ann Rheum Dis. 2007;66:143-50.

46. Kremer JM, Russell AS, Emery P, et al. Long-term safety, efficacy and inhibition of radiographic progression with abatacept treatment in patients with rheumatoid arthritis and an inadequate response to methotrexate: 3-year results from the AIM trial. Ann Rheum Dis. 2011;70:1826-30.

47. Emery P, Keystone E, Tony HP, et al. IL-6 receptor inhibition with tocilizumab improves treatment outcomes in patients with rheumatoid arthritis refractory to anti-tumour necrosis factor biologicals: results from a 24-week multicentre randomised placebo-controlled trial. Ann Rheum Dis. 2008;67:1516-23.

48. Genovese MC, Tena CP, Covarrubias A, et al. Subcutaneous abatacept for the treatment of rheumatoid arthritis: longterm data from the ACQUIRE trial. J Rheumatol. 2014;41:629-39.

49. Genovese MC, Covarrubias A, Leon G, et al. Subcutaneous abatacept vs. intravenous abatacept: a phase IIIb noninferiority study in patients with an inadequate response to methotrexate. Arthritis Rheum. 2011;63:2854-64.

50. Burmester GR, Rubbert-Roth A, Cantagrel A, et al. A randomised, double-blind, parallel-group study of the safety and efficacy of subcutaneous tocilizumab vs. intravenous tocilizumab in combination with traditional disease-modifying antirheumatic drugs in patients with moderate to severe rheumatoid arthritis (SUMMACTA study). Ann Rheum Dis. 2014;73:69-74.

51. Kivitz A, Olech E, Borofsky M, et al. Subcutaneous Tocilizumab vs placebo in combination with disease modifying antirheumatic drugs in patients with rheumatoid arthritis. Arthritis Care Res (Hoboken). 2014;66:1653-61.

52. Jones G, Sebba A, Gu J, et al. Comparison of tocilizumab monotherapy vs. methotrexate monotherapy in patients with moderate to severe rheumatoid arthritis: the AMBITION study. Ann Rheum Dis. 2010;69:88-96.

53. Maini RN, Taylor PC, Szechinski J, et al. Doubleblind randomized controlled clinical trial of the interleukin-6 receptor antagonist, tocilizumab, in European patients with rheumatoid arthritis who had an incomplete response to methotrexate (the CHARISMA study). Arthritis Rheum. 2006;54:2817-29.

54. Smolen JS, Beaulieu A, Rubbert-Roth A, et al. Effect of interleukin-6 receptor inhibition with tocilizumab in patients with rheumatoid arthritis (OPTION study): a double blind, placebocontrolled, randomised trial. Lancet. 2008;371:987-97.

55. Genovese MC, McKay JD, Nasonov EL, et al. Interleukin-6 receptor inhibition with tocilizumab reduces disease activity in rheumatoid arhtritis with inadequate response to disease-modifying antirheumatic drugs: the tocilizumab in combination with traditional disease-modifying antirheumatic drug therapy (the TOWARD study). Arthritis Rheum. 2008;58:2968-80.

56. Nishimoto N, Miyasaka N, Yamamoto K, et al. Long-term safety and efficacy of tocilizumab, an anti-interleukin-6 receptor monoclonal antibody, in monotherapy, in patients with rheumatoid arthritis (the STREAM study): evidence of safety and efficacy in a 5-year extension study. Ann Rheum Dis. 2009;68:1580-4. 
57. Keen HI, Emery P. How should we manage early rheumatoid arthritis? From imaging to intervention. Curr Opin Rheumatol. 2005;17:280-5.

58. RoActemra $162 \mathrm{mg}$ solution for injection in prefilled syringe. Available from: https://www. medicines.org.uk/emc/medicine/28809. Accessed September 1, 2014.

59. Pivot X, Gligorov J, Müller V, et al. Preference for subcutaneous or intravenous administration of trastuzumab in patients with HER2-positive early breast cancer (PrefHer): an open-label randomised study. Lancet Oncol. 2013;14:962-70.

60. Barbee MS, Harvey RD, Lonial S, et al. Subcutaneous vs. intravenous bortezomib: efficiency practice variables and patient preferences. Ann Pharmacother. 2013;47:1136-42.

61. Pivot X, Gligorov J, Müller V, et al. Patients' preferences for subcutaneous trastuzumab vs. conventional intravenous infusion for the adjuvant treatment of HER2-positive early breast cancer: final analysis of 488 patients in the international, randomized, two-cohort PrefHer study. Ann Oncol. 2014;25:1979-87.
62. British Society for Rheumatology. Guidelines for the use of intravenous tocilizumab in the treatment of adult patients with rheumatoid arthritis. Published 2013.

63. Jansen JP, Buckley F, Dejonckheere F, et al. Comparative efficacy of biologics as monotherapy and in combination with methotrexate on patient reported outcomes (PROs) in rheumatoid arthritis patients with an inadequate response to conventional DMARDs-a systematic review and network meta-analysis. Health Qual Life Outcomes. 2014;12:102.

64. Gabay C, Emery P, van Vollenhoven R, et al. Tocilizumab monotherapy vs. adalimumab monotherapy for treatment of rheumatoid arthritis (ADACTA): a randomised, double-blind, controlled phase 4 trial. Lancet. 2013;381:1541-50.

65. Ogata A, Tanimura K, Sugimoto T, et al. Phase III study of the efficacy and safety of subcutaneous vs. intravenous tocilizumab monotherapy in patients with rheumatoid arthritis. Arthritis Care Res. 2014;66:344-54. 